Int. J. Electrochem. Sci., 16 (2021) Article ID: 210747

International Journal of

ELECTROCHEMICAL

SCIENCE

www.electrochemsci.org

\title{
Synergistic effect of dispersant and wetting reagent on wettability, thermal Stability and electrochemical properties of PVDF-coating polyethylene separator for lithium-ion batteries
}

\author{
Ji Yan", Xiao-Kai Ma, Min-Yun Wang, Jun-Peng Ni, Ke-Zheng Gao, Yong Zhang, Li-Zhen Wang* \\ School of Materials and Chemical Engineering, Zhengzhou University of Light Industry, Zhengzhou \\ 450001, Henan, PR China \\ *E-mail: jiyan@zzuli.edu.cn, wlz@zzuli.edu.cn
}

doi: $10.20964 / 2021.07 .49$

Received: 2 February 2021 / Accepted: 10 March 2021 / Published: 31 May 2021

\begin{abstract}
Aim to improve the physical and related electrochemical properties of surface-coating separator, in this article, two kinds of dispersant and four kinds of wetting reagent were utilized to investigate their synergistic effect on the PVDF-coated polyethylene (PE) separator. After characterized with contact angle, slurry viscosity, electrolyte uptake ability and high-temperature baking, the PVDF-coating PE separator prepared under assistance of perfluorinated octylic acid sodium as dispersant and ethylene bis stearic acid amide as wetting reagent was assembled into $\mathrm{MCMB} / / \mathrm{Li}$ asymmetric battery. The results show that the PVDF-coating PE separator possesses reduced contact angle, improved electrolyte uptake ability and enhanced thermal shrinkage stability. Furthermore, the assembled battery with PVDF-coating PE separator can provide $304.2 \mathrm{mAh} \mathrm{g}^{-1}$ of specific capacity with capacity retention reaching $93.2 \%$ after 50 cycles at $0.5 \mathrm{C}$. The rate-recovering efficiency can back up to $95.1 \%$ at $0.1 \mathrm{C}$ after cycling at various rates. In comparison with bare PE, the battery with PVDF-coating PE separator demonstrates improved rate property and enhanced cycling stability. Even after $60 \%$ over-charging for 20 cycles at $0.2 \mathrm{C}$, the battery with optimal condition separator can possess $84.9 \%$ of its initial specific capacity at $0.1 \mathrm{C}$, strongly proven the superior over-charging tolerance. The synergistic effect between dispersant and wetting reagent can be utilized efficiently in preparation of high-quality separator for lithium ion batteries.
\end{abstract}

Keyword: Synergistic effect; Separator; Electrochemical properties; Lithium ion batteries.

\section{$\underline{\text { FULL TEXT }}$}

(C) 2021 The Authors. Published by ESG (www.electrochemsci.org). This article is an open access article distributed under the terms and conditions of the Creative Commons Attribution license (http://creativecommons.org/licenses/by/4.0/). 